\title{
Interventional Role of Job Satisfaction in the Effectiveness of Leadership Styles on Organizational Commitment
}

\author{
Alireza Golabdost ${ }^{1}$ \\ Mohammad Rezaei*1 \\ ${ }^{1}$ Master of Business Administration, Tehran University , Kish International Campus \\ *Corresponding Author Email: Mohammad.rezaei110@yahoo.com
}

\section{Doi:10.5901/mjss.2016.v7n5s1p186}

\section{Abstract}

The aim of this study is to review the literature in the field of leadership styles and organizational commitment to develop a structural model in order to examine the effect of leadership styles on job satisfaction and organizational commitment of the employees of project-based companies. The proposed model was developed based on relationships between research variables as well as findings of previous researchers and tested using structural equation modeling. The study population consisted of all employees of MAPNA Company in Tehran. To collect the data, a field study was conducted on a sample of 128 people from the population. Data collected was also analyzed using SPSS and AMOS statistical software. The findings indicated that leadership styles (supportive, participative and directive) significantly affect employees' job satisfaction and commitment to the organization.

Keywords: leadership style, job satisfaction, organizational commitment, project-oriented companies, structural equation

\section{Introduction}

In recent years, organizational commitment and job satisfactions have been studied by many researchers in the field of human resources. This is because these variables are of the most important factors determining organizational performance and effectiveness. Some studies confirmed that there is a strong relationship between organizational commitment and job satisfactions. When employees are dissatisfied with their jobs, they will be less committed to their organization so they look for another job and leave the organization. If there are no such opportunities, they may leave the organization emotionally or psychologically (Lock and Crawford, 2004). Therefore, organizational commitment and job satisfaction are important characteristics to evaluate employees' intention to leave the organization or cooperate with it. In previous studies, several factors have been proposed as factors affecting job satisfaction and organizational commitment. For example, researchers have found that leadership and organizational culture have a significant impact on job satisfaction and organizational commitment (Lock and Crawford, 2001).

Effective leadership is essential for any project contracting and leadership behavior is an important variable affecting the success of project management. In practice, many construction projects are faced with problems whose main cause often can be traced to the project managers. Some of these managers may have the capabilities or features that are not commensurate with the nature of their job. In addition, they may use inappropriate leadership styles in dealing with their subordinates during construction projects. Effective performance and beneficial outcomes of subordinates are always desirable but they do not always function that perfect. People usually respond to only one particular leadership style properly. The best style will guide them towards being efficient at work. Construction industry (contracting) is one of the most important industrial sectors in developing countries like Iran (Limsila and Ogunlana, 2008).

Appropriate leadership style of project managers is essential for the growth and survival of this industry. To achieve the best level of performance of subordinates, project managers must find the right leadership style and use it. They should also recognize individual needs of subordinates and their goals in life. Study on leadership in the field of construction project management is of greater importance because it can largely affect work performance and projects' outputs. Enjoying an appropriate leadership style can favorably enhance employees' performance and facilitate construction projects (Nguyen et al, 2004).

Furthermore, adopting a proper leadership style will be followed by employees' satisfaction. Employees who are satisfied with their jobs will make more efforts at work. This study aims to examine leadership behavior of contracting projects managers (construction) and test the relationships between a) three leadership styles and job satisfaction and $b$ ) employees' commitment and job satisfaction. In order to realize the research objectives, a conceptual model is developed 
including structural relationships between three leadership styles (supportive, participatory, directive), organizational commitment and job satisfaction which is tested using structural equation modeling approach. Then, theoretical foundations of leadership styles are overviewed to provide a framework to create the relationship between leadership styles and organizational commitment. Afterwards, research methodology is discussed and in the end, findings, practical implications and study limitations are represented.

\section{Theoretical Framework and Conceptual Model}

\subsection{Leadership}

According to Daft (2005), leadership is an influence process by which a person's behavior is to change others' behavior and opinions and this influence must be legitimated and changes should occur in line with one's goals. Researchers have identified and developed so many dimensions or aspects of leadership behavior some of which include democratic versus authoritarian approach, task-oriented versus individual-oriented and contingency approaches. Currently, the most influential contingency approach leadership is the path-goal theory introduced by Robert House (Robins, 2005). According to the path-goal theory, subordinates are motivated by leader as far as leader's behavior affects employees' performance through triggering some behaviors (paths) which lead to desired rewards (goals). Of course, it is assumed that receiving rewards depends on effective performance.

A leader also may act in different ways in different situations. These researchers wanted to find out what manners of leadership are the most successful ones in terms of members' cooperation and meeting organizational objectives. The main basis of such theory is that leader's duty is to help subordinates and followers to achieve goals. To ensure that members' objectives are consistent with overall goals of the group or organization, a leader should not deprive them of any kind of guidance and support. According to the path-goal theory, leader's behavior can be acceptable to subordinates to the extent that they assume such behavior as a resource that can make them satisfy now and in the future. Leader's behavior is a drive that motivates employees in such a way that 1) provide them with good performance which makes them satisfy, 2) brings guidance, supports and rewards with it which are required for a good performance (Derue et al, 2011).

There are four leadership styles according to the path-goal theory including 1) directive leadership (which develop programs, gives instructions necessary and direct employees accurately on what is needed to be done), 2) supportive leadership (here leader has a friendly relationship with subordinates and tries to meet their needs), 3) participative leadership (leader consults with subordinates and tries to get informed of their opinions and comments before making any decisions) and 4) achievement-oriented leadership (such leaders set difficult and inaccessible goals and ask their employees to achieve those goals in the best way possible). According to the path-goal theory, it is assumed that given the existing circumstances a leader can simultaneously adopt any or all of these behaviors (Ying and Bin Ahmad, 2009). The study results confirm the basis of this theory's logic, that is, when leader tends to make up the shortages (whether about work or employees) performance and job satisfaction of organization's staff and members will increase. But when affairs are clear and specified and leader spends his time on explaining all duties, it won't make any suitable changes because in employees' mind such behavior is just stating the obvious and an insult to them. The point that must be kept in mind is that none of the leadership styles discussed is ideal for any situation (Swid, 2014).

Studies on leadership behavior through the path-goal theory have been conducted in areas such as business strategy in small and medium-sized enterprises, company managers, steel industry, automotive industry and market orientation of companies. Importantly, in carious societies depending on individualism and collectivism, cultural and ethnic diversity, different leadership styles are used (Chan and Mack, 2011).

\subsection{Organizational commitment}

Organizational commitment is the third attitude of job attitudes which is a condition where organization's workers believe that they are represented through their goals and wish to remain a member of that organization. So a high level of job dependence means that someone's attached to a specific profession and that they introduce themselves through that job however organizational commitment means an individual's attachment to a particular organization. In fact, results obtained from investigations suggest that organizational commitments is used to predict and explain someone's behavior (much more than job satisfaction) and that through this variable, it'll be easier to predict the rate of employees' absenteeism and turnover (Brunetto and Farr-Wharton, 2006). Allan and Meyer (1999) proposed a tripartite model of organizational commitment which has the following components:

1. Affective commitment: this part is defined as a sense of belonging to an organization which is recognized 
through acceptance of organizational values as well as desire to remain on the job.

2. Assignment or normative commitment: assignment commitment is defined as a perceived duty to support organization and its activities and reflects the sense of indebtedness and obligation to remain on the job upon which people think that continuing to work and support the organization is a debt they have to pay back.

3. Continuance commitment: it is resulted from understanding the increase in missing costs in the organization. Missing costs are expenses spend on an activity or a project that are not returnable. So if someone is continuously committed to the organization, they will be sensitive to such increase in costs.

Developers of this model believe that it is better to consider normative, affective and continuance parts as components of commitment rather than its specific types. Because, if there are certain types of commitments, the member will have a slight sense of duty and obligation to stay in the organization (Alan and Meyer, 1999).

\subsection{Job satisfaction}

Job satisfaction is one of the most important behavioral issues in the human realm of organizations which in turn determines many other organizational variables. There are different definitions of job satisfaction. In some of them, this concept is defined as employees' emotional and attitudinal response to their job. Simply it can be said that job satisfaction is a degree to which people love their jobs. So some people enjoy their job and find it as an important part of their lives. While some other hate it and do it only because they have to. According to a similar definition, job satisfaction is the difference between the amount of intensity of individual's needs and how much they are met at work. In other words, job satisfaction here is a direct function of the degree to which the environment is consistent with the structure of someone's needs. Some experts consider job satisfaction as a multidimensional concept that includes internal and external aspects. Satisfaction's internal resources refer to a person's personality traits such as the ability to initiate and communicate with supervisors which are called qualitative aspects of the job. External resources of satisfaction are contingent and dependent on environmental conditions such as payment, promotion or job security (Lock and Crawford, 1999).

\subsection{Relationships between variables and hypotheses}

According to Apple Baum et al (2004) and Yousef (2000), the relationship between leadership behavior and job satisfaction has attracted a lot of attention over the past decade. Researchers such as Kim (2002) and Ying and Bin Ahmad (2009) also acknowledged that leadership style dramatically affects employees' job satisfaction and thus their commitment to the organization. Accordingly, research hypotheses can be stated as follows:

The first hypothesis $(\mathrm{H} 1)$ : there is a significant direct relationship between supportive leadership style and job satisfaction.

The second hypothesis $(\mathrm{H} 2)$ : there is a significant direct relationship between directive leadership style and job satisfaction.

The third hypothesis (H3): there is a significant direct relationship between participative leadership style and job satisfaction.

The forth hypothesis $(\mathrm{H} 4)$ : there is a significant direct relationship between job satisfaction and organizational commitment. as follows:

Regarding the abovementioned discussions and hypotheses developed, the conceptual model can be presented

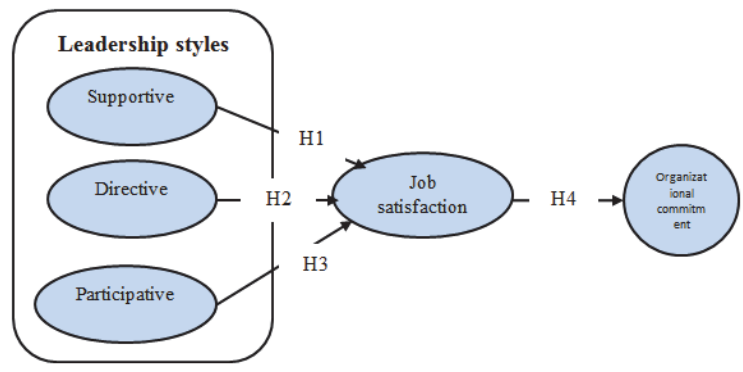

Figure 1. Research conceptual model 


\section{Methodology}

The present study is a descriptive-applied research performed through survey method. The population consisted of all project employees of MAPNA Company in Tehran. The measure to choose this company was project-orientation of its activities. First a pilot study was done on a small part of the population including 30 personnel of MAPNA Group and standard deviation was determined. Then, sample size was estimated including 128 people using Cochran's formula at error level of $5 \%$ and accuracy of 0.1 . In this study, convenience sampling method was used. First, we visited MAPNA Company in Tehran and randomly selected the sample subjects among its employees. To collect the data, a research made questionnaire was used comprised of two parts including questions on three leadership styles (9 items), job satisfaction (3 items) and organizational commitment (3 items). In the first part, respondents were asked to rank how much their leaders use leadership styles (supportive, participative and directive) on a five-point Likert scale ranged from 1 (very low) to 5 (very high). Questions related to this part are adapted from study done by Harris and Ogbonna (2011). In the second part, subjects were asked some questions to measure their job satisfaction and organizational commitment. Questions of this part were adopted from study conducted by Ying and Bin Ahmad (2009). Respondents were asked to rank their job satisfaction and organizational commitment on a 5-point Likert scale from 1 (very low) to 5 (very high). It is worth noting that considering research topic scope and emphasis on affective commitment in the literature reviewed, this study also stresses only on this variable. Data analysis is performed in two stages. First, validity and reliability of the questionnaire was assessed. Then, to test hypotheses and fit the model, research structural model was statistically measured. In the first step, confirmatory factor analysis method was used to examine questionnaire validity. Validity test includes convergent validity and discriminant validity. Convergent validity shows whether questions can be indicative of their corresponding factor. Discriminant validity measures the significance of difference between these two factors. Convergent validity and discriminant validity were investigated respectively using factor loadings correlation coefficient methods. Values of factor loading that are greater than 0.7 represent desirability of convergent validity. In case that correlation coefficient between factors is less than 0.85 , it can be argued that assessment tool has an appropriate discriminant validity (Kline, 2005). Cronbach's alpha coefficient was used to determine the reliability. If value of Cronbach's alpha is greater than 0.7 , questionnaite reliability is acceptable (Hair et al, 2006).

To confirm or reject the hypotheses and fit the model in the second step, structural equation modeling (SEM) was performed using AMOS16 software. Parameters and model fitting index were estimated based on maximum likelihood (ML) method. Indicators used in this study included Chi-Square (2X), goodness of fit index (GFI), adjusted goodness of fit index (AGFI), comparative fit index (CFI), Akaike information criterion (AIC), Tucker-Lewis index (TLI), and root mean square error of approximation (RMSEA). Smaller values of Chi-Square indicated a proper fit of model. Some sources suggest that to accept a model, the ratio of Chi-Square to degree of freedom must be less than 3 . The closer the GFI obtained value to 1 is, the more proper and fitting the model will be (this index is between 1 and 0 ). Appropriate amount of AGFI which is similar to GFI and is placed between 1 and 0 is value that is closer to number 1 . CFI that is also known as Bentler comparative fit index is between zero and one and the closer it is to 1, the more proper it will be. AIC or maximum likelihood estimation index is considered a good indicator to compare different models that have been questioned on a data set. A model with lower value is more fitted. The value estimated in TLI or non-normed fit index that is equal to 0.95 or more indicates the suitability of model. The values less than 0.08 are acceptable in RMSEA index (Harington, 2008).

In addition to above indices, there are also some values for questions and items called factor loadings and measurement error. Factor loadings represent correlation between variables or factors. Positive loadings imply the nature of hidden and underlying aspect of the factor and negative loadings help to interpret by saying that what that factor is. The greater the value is, the more weight should be given to it (Hair et al, 2006).

\section{Findings}

The results of descriptive statistics indicated that respondents included $85.5 \%$ male and $14.5 \%$ female. $66.1 \%$ of them had BA degree and $33.9 \%$ had master's degree or higher. $46.4 \%$ of the participants aged between 20 to $30,34.6 \%$ of them aged between 31 to 40 and 19.0\% of them were higher than 40. Table 1 demonstrates results related to mean, standard deviation, factor loadings and Cronbach's alpha coefficient of the variables. As can be seen, all factor loadings higher than 0.7 are acceptable which represents favorable convergent validity of data collection tool. Cronbach's alpha coefficient of all variables is also higher than 0.7 which indicates assessment tool has an appropriate reliability. 
Table 1. Descriptive statistics, factor loadings and Cronbach's alpha coefficient

\begin{tabular}{|c|c|c|c|c|c|}
\hline Factor & \multicolumn{5}{|c|}{\begin{tabular}{|l|l|} 
Question|Mean Standard deviation & Factor loadings|Cronbach's alpha \\
\end{tabular}} \\
\hline \multicolumn{6}{|l|}{ Supportive leadership style } \\
\hline Manager helps employees to do their duties with more willingness. & Sup1 & 3.64 & 0.812 & 0.917 & \multirow{2}{*}{$(0.748)$} \\
\hline Tries to provide staff welfare. & Sup2 & 3.88 & 0.774 & 0.720 & \\
\hline Treats all personnel equally and fairly. & Sup3 & 3.72 & 0.789 & 0.713 & \\
\hline \multicolumn{6}{|l|}{ Participative leadership style } \\
\hline Listens to the viewpoints of subordinates before reaching a decision. & Part1 & 3.48 & 0.819 & 0.800 & \multirow{2}{*}{$(0.771)$} \\
\hline Consults with subordinates before taking action. & Part2 & 3.13 & 0.897 & 0.789 & \\
\hline Asks subordinates to present their suggestions. & Part3 & 3.37 & 0.843 & 0.692 & \\
\hline \multicolumn{6}{|l|}{ Directive leadership style } \\
\hline Describes duties and tasks that must be done. & Dir1 & 3.96 & 0.755 & 0.760 & \multirow{2}{*}{$(0.690)$} \\
\hline Uses certain performance standards. & Dir2 & 3.23 & 0.936 & 0.741 & \\
\hline Provides duties that must be done in the form of a written plan. & Dir3 & 3.81 & 0.836 & 0.801 & \\
\hline \multicolumn{6}{|l|}{ Job satisfaction } \\
\hline I'm satisfied with what I do. & Sat1 & 3.48 & 0.926 & 0.824 & \multirow{3}{*}{$(0.821)$} \\
\hline I'm satisfied with promotional opportunities. & Sat2 & 3.62 & 0.810 & 0.817 & \\
\hline I'm satisfied with my salary. & Sat3 & 3.06 & 0.955 & 0.729 & \\
\hline \multicolumn{6}{|l|}{ Organizational commitment } \\
\hline I enjoy talking about the organization to people outside of it. & Com1 & 3.37 & 0.938 & 0.813 & $(0.849)$ \\
\hline I have a strong sense of belonging to this organization. & Com2 & 3.54 & 0.823 & 0.826 & \\
\hline This organization gives me a sense of identity and meaningfulness & Com3 & 3.33 & 9.33 & 0.738 & \\
\hline
\end{tabular}

Furthermore, according to the correlation coefficients in table 2 we can say that correlations among variables are less than 0.85 proposed which implies discriminant validity of the tool. It should be noted that significance of correlations between variables was tested at $P \leq 0.001$. According to the results of Pearson correlation test, all variables are significantly and positively related which suggest a direct relationship between independent variables (supportive, participative and directive leadership styles) and dependent variables (job satisfaction and organizational commitment).

Table 2. Correlation coefficients between variables

\begin{tabular}{|l|c|c|c|c|c|}
\hline Correlation & Supportive style & Participative style & Directive style & Job satisfaction & Organizational commitment \\
\hline Supportive style & 1 & $0.529^{*}$ & $0.621^{*}$ & $0.552^{*}$ & $0.437^{*}$ \\
\hline Participative style & $0.529^{*}$ & 1 & $0.650^{*}$ & $0.685^{\star}$ & $0.764^{*}$ \\
\hline Directive style & $0.621^{*}$ & $0.650^{*}$ & 1 & $0.605^{*}$ & $0.516^{*}$ \\
\hline Job satisfaction & $0.552^{*}$ & $0.685^{*}$ & $0.605^{*}$ & 1 & $0.663^{*}$ \\
\hline Organizational commitment & $0.437^{*}$ & $0.764^{*}$ & $0.516^{*}$ & $0.663^{*}$ & 1 \\
\hline
\end{tabular}

Structural equation modeling (SEM) method was used to achieve research objectives. The chi-square value in this study is equal to 42.869 with degree of freedom of 18 whose ratio (2.382) is within the optimal range. Values of fitting indices $(\mathrm{GFI}=0.964, \mathrm{NFI}=0.962, \mathrm{CFI}=0.977, \mathrm{TLI}=0.954, \mathrm{AGFI}=0.909, \mathrm{AIC}=96,869)$ are acceptable and significant at $5 \%$ level. RMSEA value obtained here is 0.073 which is less than desirable amount proposed (less than 0.08 ). In fact, results of SEM represent a perfect fit of the proposed model in this study. Figures 2 and 3 illustrate standardized and nonstandardized regression coefficients of the research structural model. 


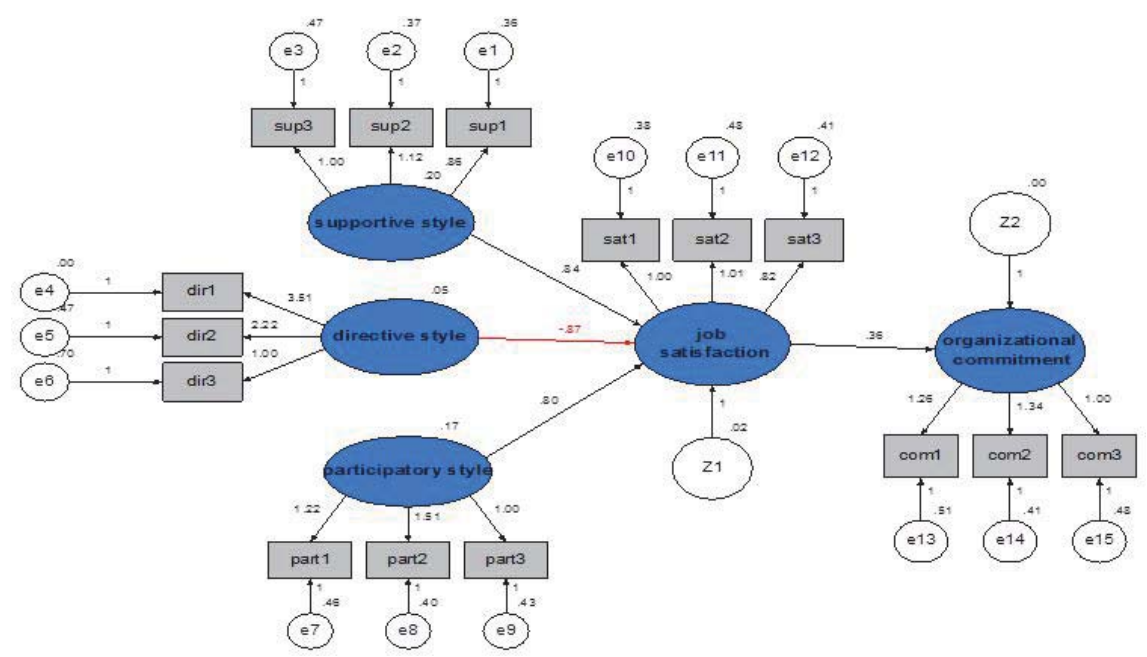

Figure 2. Non-standardized regression coefficients of the proposed model

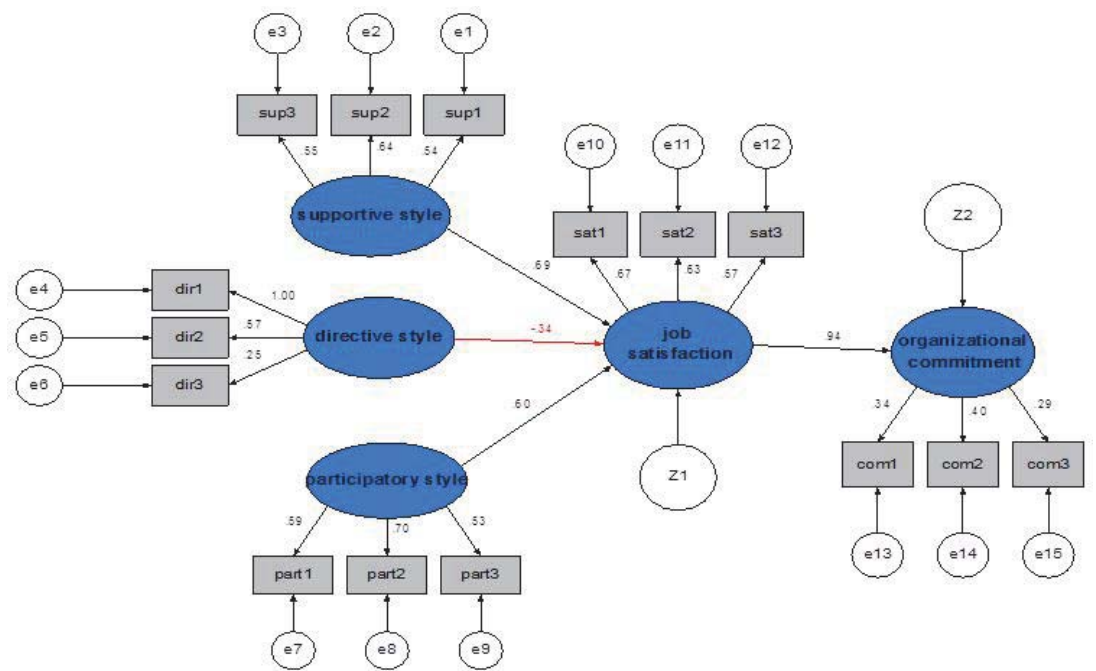

Figure 3. Standardized regression coefficients of the proposed model

The results of hypotheses testing are summarized in table 3. As you can see, all the relations suggested are confirmed. In fact, leadership styles including supportive, participative and directive styles had a significant impact on employees' job satisfaction (hypotheses 1, 2 and 3). However, directive style had a negative effect on job satisfaction of employees. Moreover, employees' job satisfaction remarkably affected their commitment to the organization (the forth hypothesis).

Table 3. Summary of data analysis results using maximum likelihood

\begin{tabular}{|c|l|l|c|c|c|c|c|c|}
\hline Hypothesis & Independent variable & Dependent variable & $\begin{array}{c}\text { Path } \\
\text { coefficients }\end{array}$ & $\begin{array}{c}\text { Standardized } \\
\text { coefficients }\end{array}$ & $\begin{array}{c}\text { Standard } \\
\text { error }\end{array}$ & $\begin{array}{c}\text { Critical } \\
\text { ratio }\end{array}$ & $P$ & Result \\
\hline First $(\mathrm{H} 1)$ & Supportive leadership style & Job satisfaction & 0.836 & 0.687 & 0.137 & 6.099 & $* \star$ & Confirmed \\
\hline Second (H2) & Directive leadership style & Job satisfaction & -0.867 & -0.337 & 0.244 & -3.557 & $* \star$ & Confirmed \\
\hline Third $(\mathrm{H} 3)$ & Participative leadership style & Organizational commitment & 0.799 & 0.596 & 0.104 & 5.874 & $* \star$ & Confirmed \\
\hline Forth $(\mathrm{H} 4)$ & Job satisfaction & Organizational commitment & 0.356 & 0.941 & 0.087 & 4.070 & $* \star$ & Confirmed \\
\hline Note: ${ }^{*}$ significant at $\mathrm{P}<0.001,{ }^{*}$ significant at $\mathrm{P}<0.01$ level.
\end{tabular}




\section{Discussion, Conclusion and Suggestions}

The aim of this study was to develop a structural model to evaluate the interventional role of job satisfaction in effectiveness of three leadership styles on employees' organizational commitment in project-oriented companies. The results show that supportive, directive and participative styles respectively had the highest impact on employees' job satisfaction in MAPNA Company. However, directive leadership style had a negative effect on employees' job satisfaction. These findings are consistent with the results obtained in studied conducted by researchers such as Apple Baum et al (2004), Yousef (2000), Kim (2002) and Ying and Bin Ahmad (2009) indicating that leadership style applied by managers affect employees' job satisfaction. Also, results confirmed that job satisfaction directly affects organizational commitment. This corresponds with the results of Lock and Crawford (2004) and Lock and Crawford (2001) stating that employees' job satisfaction affects their commitment to the organization. By reviewing the literature in the field of information technology we find out that this is the first study to examine the effects of three leadership styles according to the path-goal theory on organizational commitment through influencing job satisfaction in project-oriented companies. The findings of this study can help project-oriented organizations to deeply understand advantages a desired leadership style that is the most suited for their business environment. So by using these styles properly they can reduce employees' dissatisfaction and increase their commitment to the company. According to the results, some suggestions can be offered to MAPNA managers and supervisors. Leaders should understand the effect of leadership style they are using on employees' organizational commitment and note that the success they achieve on their efforts is dependent on shared values and norms in the organization. So to increase their effectiveness, leaders must change their leadership styles to create synergy with the corporate culture. Generally speaking, managers are suggested to take advantage of contingency approach to use leadership styles and behavior. This study has been faced with some limitations. For example, this study was conducted in Tehran. This reduces the generalizability of the findings. Performing a similar study on a larger scale can decrease the limitations and increase the generalizability level. Besides, given the sample size it is recommended that this study be replicated using a larger sample and in other project-oriented companies.

\section{References}

Allen, N. and Meyer, J. (1990), "The measurement and antecedents of affective, normative and continuance commitment to the organization", Journal of Occupational Psychology, Vol. 63, pp. 1-18.

Brunetto, Y. and Farr-Wharton, R. (2003), "The commitment and satisfaction of lower-ranked police officers: lessons for management", Policing: An International Journal of Police Strategies \& Management, Vol. 26 No. 1, pp. 43-63.

Chan, S. C.H. and Mak, W.M. (2014),"Transformational leadership, pride in being a follower of the leader and organizational commitment", Leadership \& Organization Development Journal, Vol. 35 No. 8 pp. 674-690.

Daft, R.L. (2005), The Leadership Experience, 3rd ed., Thomson-Southwestern, Vancouver.

Derue, D. S., Nahrgang, J. D., Wellman, N., and Humphrey, S. E. (2011), Trait and Behavioral Theories Of Leadership: An Integration and MetaAnalytic Test Of Their Relative Validity, Personnel Psychology, Vol. 64, pp. 7-52.

Hair, J.F., Black, W.C., Babin, B.J., Anderson, R.E. and Tatham, R.L. (2006), Multivariate Data Analysis, 6th ed., Prentice-Hall, Upper Saddle River, NJ.

Harrington, D. (2008), Confirmatory Factor Analysis, Oxford University Press.

Harris, L. C. and Ogbonna, E. (2001),"Leadership style and market orientation: an empirical study", European Journal of Marketing, Vol. 35 No. $5 / 6$ pp. $744-764$.

Kline, R. B. (1998). Principles and practice of structural equation modeling. NY: Guilford Press.

Limsila, K. and Ogunlana, S. O. (2008),"Performance and leadership outcome correlates of leadership styles and subordinate commitment", Engineering, Construction and Architectural Management, Vol. 15 No. 2 pp. 164-184.

Lok, P. and Crawford, J. (1999),"The relationship between commitment and organizational culture, subculture, leadership style and job satisfaction in organizational change and development", Leadership \& Organization Development Journal, Vol. 20 No. 7 pp. 365-374.

Lok, P. and Crawford, J. (2001), "Antecedents of organizational commitment and the mediating role of job satisfaction", Journal of Managerial Psychology, Vol. 16 No. 8, pp. 594-613.

Lok, P. and Crawford, J. (2004),"The effect of organizational culture and leadership style on job satisfaction and organizational commitment", Journal of Management Development, Vol. 23 No. 4 pp. 321-338.

Nguyen, L.D., Ogunlana, S.O. and Lan, D.T.X. (2004), "A study on project success factors in large construction projects in Vietnam", Engineering, Construction and Architectural Management, Vol. 11 No. 6, pp. 404-13.

Robbins, S.P. (2005), Organizational Behavior, 11th ed., Pearson Prentice-Hall, Englewood Cliffs, NJ.

Swid, A. (2014),"Police members perception of their leaders' leadership style and its implications", Policing: An International Journal of Police Strategies \& Management, Vol. 37 Iss 3 pp. $579-595$.

Yiing, L. H. and BinAhmad, K.Z. (2009),"The moderating effects of organizational culture on the relationships between leadership behaviour and organizational commitment and between organizational commitment and job satisfaction and performance", Leadership \& Organization Development Journal, Vol. 30 No. 1 pp. 53-86. 